\title{
HUBUNGAN KECEMASAN DENGAN KELANCARAN \\ PENGELUARAN ASI PADA IBU POST PARTUM \\ SELAMA DIRAWAT DI RUMAH SAKIT IBU DAN ANAK KASIH IBU MANADO
}

\author{
Zulfikar Mardjun \\ Grace Korompis \\ Sefti Rompas \\ Program Studi Ilmu Keperawatan Fakultas Kedokteran \\ Universitas Sam Ratulangi \\ Email : ikbalmardjun06@gmail.com
}

\begin{abstract}
Smooth breastfeeding is influenced by several factors, one of which is psychological factors, namely anxiety. In general, postpartum mothers often experience fatigue and mood swings such as anxiety; about themselves and about their new-born baby. This anxiety can affect the smoothness of breastfeeding in post partum mothers. The purpose of this study was to determine the relationship between anxiety and smooth release of breast milk in post partum mothers while being treated at Mother and Baby Hospital, Kasih Ibu Manado. The method of this research uses cross sectional research design. The sample consisted of 68 respondents with a non probability sampling method with a purposive sampling technique. The results using the Chi-Square did not fulfill the requirements thus continued with the Fisher Exact test at the significance level of $95 \%$, obtained by the value $\rho$ Value 0.001 smaller than the significant value of 0.05 . In conclusion, there is a relationship between anxiety and the smooth releasee of breast milk in post partum mothers while being treated at Kasih Ibu Hospital.
\end{abstract}

Keywords : Anxiety, Smooth Release of Breast Milk

Abstrak : Kelancaran pengeluaran ASI dipengaruhi oleh beberapa faktor, salah satunya faktor psikologis yaitu kecemasan. Pada umumnya ibu pasca persalinan sering mengalami kelelahan dan perubahan mood seperti kecemasan, cemas terhadap dirinya dan cemas memikirkan bayinya. Kecemasan tersebut yang dapat mempengaruhi kelancara pengeluaran ASI pada ibu post partum. Tujuan untuk mengetahui hubungan antara kecemasan dengan kelancaran pengeluaran air susu ibu pada ibu post partum selama dirawat di Rumah Sakit Ibu dan Anak Kasih Ibu Manado. Metode menggunakan desain penelitian cross sectional. Sampel terdiri dari 68 responden dengan metode pengambilan sampelsecara non probability sampling dengan teknik purposive sampling. Hasil dengan menggunakan uji Chi - Square tetapi tidak memenuhi syarat dan dilanjutkan dengan uji Fisher Exact pada tingkat kemaknaan 95\%, didapatkan nilai $\rho$ - Value 0,001 lebih kecil dari nilai signifikan 0,05. Kesimpulan ada hubungan antara kecemasan dengan kelancaran pengeluaran air susu ibu pada ibu post partum selama dirawat di Rumah Sakit Ibu dan Anak Kasih Ibu Manado.

Kata Kunci : Kecemasan, Kelancaran Pengeluaran ASI 


\section{PENDAHULUAN}

Air Susu Ibu (ASI) adalah cairan yang disekresikan oleh kelenjar payudara ibu berupa makanan alamiah atau susu terbaik bernutrisi dan berenergi tinggi yang diproduksi sejak masa kehamilan (Wiji, 2013). World Health Organization (WHO) dan United Nations International Children's Emergency Fund (UNICEF) merekomdasikan sebaiknya anak hanya diberi air susu ibu (ASI) selama paling sedikit 6 bulan dan pemberian ASI dilanjutkan sampai anak berumur 2 tahun.

Menurut data WHO (2016), cakupan ASI eksklusif di seluruh dunia hanya sekitar $36 \%$ selama periode 2007 2014. Pencapaian ASI Eksklusif di Indonesia sebesar $54,0 \%$ telah mencapai target (Kementrian Kesehatan RI, 2016). Sedangkan di Sulawesi Utara cakupan bayi yang mendapatkan ASI eksklusif adalah $39,42 \%$ atau naik dibanding tahun 2015 yang mempunyai cakupan 33,58 \% (Dinas Kesehatan Provinsi Sulawesi Utara, 2016).

Pemerintah mengatur tentang pemberian ASI dalam Undang - undang Nomor 33 tahun 2012 untuk mendukung ibu menyusui secara eksklusif. Peraturan ini menyatakan ibu wajib untuk menyusui bayinya secara eksklusif sejak bayi lahir sampai berusia enam bulan. Upaya pemerintah ini lantas mendapat sambutan positif dari dunia internasional. Tetapi pada kenyataannya, realisasi dari peraturan pemerintah tersebut masih kurang. Kegagalan dalam proses menyusui sering disebabkan karena timbulnya beberapa faktor, antara lain faktor perubahan sosial budaya, faktor psikologis, faktor fisik ibu, meningkatnya promosi susu formula, faktor petugas kesehatan, makanan ibu, berat badan lahir bayi, penggunaan alat kontrasepsi. Perubahan sosial budaya dimana ibu-ibu yang bekerja atau ibu-ibu yang mempunyai kesibukan lainnya, meniru teman atau tetangga yang menggunakan susu botol, merasa ketinggalan zaman jika menyusui. Kelancaran ASI sangat dipengaruhi oleh faktor kejiwaan karena perasaan ibu dapat mengahmbat atau meningkatkan pengeluaran oksitosin (Hardiani, R.S, 2017).

Proses menyusui terdapat dua proses penting yaitu proses pembentukan air susu (the milk production reflex) dan proses pengeluaran air susu let down reflex) yang kedua proses tersebut dipengaruhi oleh hormon yang diatur oleh hypothalamus (Badriah, 2011). Sebagaimana pengaturan hormon yang lain, hypothalamus akan bekerja sesuai dengan perintah otak dan bekerja sesuai emosi ibu (Aprilia, 2011). Kondisi kejiwaan dan emosi ibu yang tenang sangat memengaruhi kelancaran ASI. Jika ibu mengalami stres, pikiran tertekan, tidak tenang, cemas, sedih, dan tegang akan mempengaruhi kelancaran ASI (Riksani, 2012).

Ibu yang cemas akan sedikit mengeluarkan ASI dibandingkan ibu yang tidak cemas. Berdasarkan hasil penelitian Iin Febrina (2011) mengatakan bahwa terdapat hubungan antara tingkat kecemasan dengan kelancaran pengeluaran ASI ibu post partum primipara. Upaya agar ASI tetap lancar yaitu mulai dari keinginan ibu yang kuat untuk memberikan nutrisi terbaik yaitu ASI pada bayinya. Motivasi yang kuat akan berpengaruh terhadap fisik dan emosi ibu untuk menghasilkan ASI. Dengan memiliki keinginan yangkuat dan kasih sayang yang tulus dan tinggi, maka produksi ASI bisa terpacu. Salah satunya yaitu dukungan dari suami dan keluarga, kerena dukungan dari orang-orang terdekat dapat mempengaruhi kelancaran pengeluaran ASI dan terhindar dari kecemasan sehingga terciptakan suasana yang nyaman di dalam keluarga dan ibu merasa rileks dan nyaman. Dengan demikian ASI akan terproduksi dengan lancar. Jika suasana hati ibu merasa nyaman dan gembira akan mempengaruhi kelancaran ASI, sebaliknya jika ibu merasa cemas dan stress akan menghambat kelancaran pengeluaran ASI (Qiftiyah, M, 2018). 
Fenomena yang peneliti dapatkan ketika praktek klinik sebagian besar ibu pasca persalinan tidak menyusui bayinya hanya memberikan susu formula kepada bayi, sebagian ibu mengatakan hanya memberikan susu formula karena ASI tidak keluar. Salah satu faktor ASI tidak keluar dengan lancar adalah kondisi psikologis ibu seperti rasa cemas dan takut.

Survei data awal yang diambil dari RSIA Kasih Ibu Manado pada bulan Juli September 2018 didapat jumlah seluruh ibu yang melahirkan sebanyak 246 orang. Dari hasil wawancara singkat yang peneliti lakukan pada 5 ibu post partum, 3 orang ibu mengatakan ASI hanya sedikit yang keluar dan merasa cemas dan tidak percaya diri dalam memberikan ASI pada bayinya, 2 orang ibu lainnya mengatakan ASI lancar dan tidak pernah merasa cemas.

Fenomena yang terjadi saat ini, kelancaran pengeluaran ASI seringkali disebabkan oleh faktor kecemasan. Sehingga berdasarkan masalah tersebut maka peneliti tertarik melakukan penelitian dengan judul "Hubungan Kecemasan Dengan Kelancaran Pengeluaran Air Susu Ibu Pada Ibu Post Partum Selama Dirawat di Rumah Sakit Ibu dan Anak Kasih Ibu Manado".

\section{METODE PENELITIAN}

Jenis penelitian yang digunakan ialah penelitian yang bersifat analitik dengan pendekatan cross sectional. Penelitian ini dilakukan di Rumah Sakit Ibu dan Anak Kasih Ibu Manado pada tanggal 4 September - 13 Desember tahun 2018 dengan populasi sebanyak 82 orang. Pengambilan sampel pada penelitian ini dilakukan secara non probability sampling dengan teknik purposive sampling. Penentuan besar sampel menggunakan rumus slovin didapatkan sampel pada penelitian ini adalah 68 orang yang telah memenuhi kriteria inklusi : seluruh ibu post partum yang sedang dirawat di RSIA Kasih Ibu Manado, Ibu post partum yang bayinya hidup dan Ibu post partum yang menyusui. Kriteria eksklusi : ibu yang mengonsumsi obat antidepresan dan Ibu post partum yang menolak menjadi responden.

Penelitian ini menggunakan instrumen berupa kuesioner data diri dan skala tingkat kecemasan The State-Trait Anxiety Inventory (STAI) yang terdiri dari 20 item pertanyaan terdapat pernyataan yang mengindikasikan keberdaan kecemasan (presence of anxiety) yangtergolong dalam favorable item dan pernyataan yang mengindikasikan ketiadaan kecemasan (absence of anxiety) tergolong dalam unfavorable, dan kuesioner kelancaran ASI yang terdiri dari 4 pertanyaan, dengan isian dibagi dalam dua kategori yaitu Ya atau Tidak, dimana kurang lancar jika responden menjawab tidak pada salah satu pertanyaan, dan lancar jika responden menjawab ya pada semua pertanyaan.

Jenis data yang digunakan pada penelitian ini adalah data primer dan data sekunder. Data primer adalah data yang diperoleh langsung dari responden dan data sekunder data yang diperoleh dari pihak Rumah Sakit Ibu dan Anak Kasih Ibu Manado.

Pengolahan data yang diperoleh dari hasil penelitian ini diolah secara manual dengan mengelompokkan hasil dari lembar kuesioner yang dibagikan dan selanjutnya dilakukan analisis menggunakan uji statistik. Setelah itu diolah menggunakan sistem komputerisasi, tahap-tahap tersebut yaitu Editting, Coding, Proccessing, dan Cleaning.

Analisis univariat pada penelitian ini akan menghasilkan distribusi frekuensi yang memberi gambaran mengenai jumlah dan presentase. Analisis univariat dilakukan untuk menganalisa variabel kecemasan dan variabel Kelancaran pengeluaran ASI ibu post partum. Analisa bivariat merupakan analisa hasil dari variabel independen diduga mempunyai hubungan dengan variabel dependen. Analisa yang digunakan adalah hasil tabulasi silang. Untuk menguji hipotesa dilakukan analisa statistik dengan uji Chisquare pada tingkat kemaknaan 95\% ( $\rho$ Value $<0,05$ ), setelah diuji hasil tidak 
memenuhi syarat dan dilanjutkan dengan uji Fisher Exact.Melalui perhitungan Fisher Exact selanjutnya ditarik suatu kesimpulan, bila nilai $\rho$ - Value lebih kecil dari nilai $\alpha$ $(0,05)$, maka Ho ditolak dan $\mathrm{H}_{1}$ diterima, yang menunjukkan ada hubungan bermakna antara variabel dependen dengan variabel independen.

\section{HASIL dan PEMBAHASAN}

Tabel 1.Distribusi responden berdasarkan umur ibu post partum di RSIA kasih ibu manado.

\begin{tabular}{ccc}
\hline Umur & n & \% \\
\hline $21-25$ & 13 & 19,1 \\
$26-30$ & 28 & 41,2 \\
$31-35$ & 19 & 27,9 \\
$36-40$ & 6 & 8,8 \\
$41-45$ & 2 & 2,9 \\
\hline Total & $\mathbf{6 8}$ & $\mathbf{1 0 0 , 0}$ \\
\hline
\end{tabular}

Sumber : Data Primer, 2018

Hasil penelitian menunjukan bahwa dari 68 responden didapati sebagian besar responden berumur 26-30 berjumlah 28 responden (41,2\%). Faktor usia menentukan kondisi maternal dan berkaitan dengan kondisi masa kehamilan, persalinan dan menyusui. Usia ibu sangat mempengaruhi cara ibu mengambil keputusan dalam menjaga kesehatan dirinya dimana usia semakin bertambah maka pengetahuan dan pengalaman ibu akan semakin bertambah (Anggraini, 2011).

Tabel 2.Distribusi responden berdasarkan pendidikan terakhir ibu post partum di RSIA kasih ibu manado

\begin{tabular}{ccc}
\hline Pendidikan Terakhir & $\mathbf{n}$ & $\mathbf{\%}$ \\
\hline SD & 1 & 1,5 \\
SMP & 1 & 1,5 \\
SMA & 19 & 27,9 \\
D1 & 1 & 1,5 \\
D3 & 3 & 4,4 \\
D4 & 1 & 1,5 \\
S1 & 39 & 57,4 \\
S2 & 3 & 4,4 \\
\hline Total & $\mathbf{6 8}$ & $\mathbf{1 0 0 , 0}$ \\
\hline
\end{tabular}

Sumber : Data Primer, 2018
Hasil penelitian menunjukan bahwa dari 68 responden didapati sebagian besar responden berpendidikan terakhir $\mathrm{S} 1$ berjumlah 39 responden $(57,4 \%)$.

Pendidikan ibu menjadi faktor yang penting dalam pemberian ASI pada bayi, tingkat pendidikan rendah terkadang sulit menerima penjelasan tentang pemberian ASI dan tingkat pendidikan yang baik akan mudah dalam menerima informasi terutama tentang pemenuhan kebutuhan nutrisi anak sehingga kecukupan gizi anak bisa terjamin. Pada umumnya ibu yang berpendidikan sedang sampai tinggi dapat menerima hal-hal yang baru dan dapat menerima perubahan untuk memelihara kesehatan khususnya tentang pemberian ASI. Mereka bisa terdorong untuk mencari tahu, mencari pengalaman sehingga informasi yang diperoleh akan menjadi pengetahuan dan diterapkan pada kehidupannya (Hartini, 2014).

Tabel 3.Distribusi responden berdasarkan pekerjaan ibu post partum di RSIA kasih ibu manado

\begin{tabular}{ccc}
\hline Pekerjaan & n & \% \\
\hline IRT & 30 & 44,1 \\
Honorer & 3 & 4,4 \\
Guru & 1 & 1,5 \\
Pendeta & 1 & 1,5 \\
Swasta & 15 & 22,1 \\
Wiraswasta & 3 & 4,4 \\
Kar. BNI & 1 & 1,5 \\
Peg. BUMN & 6 & 8,8 \\
Dokter & 3 & 4,4 \\
Perawat & 1 & 1,5 \\
PNS & 4 & 5,9 \\
\hline Total & $\mathbf{6 8}$ & $\mathbf{1 0 0 , 0}$ \\
\hline
\end{tabular}

Sumber : Data Primer, 2018

Hasil penelitian menunjukan bahwa dari 68 responden didapati sebagian responden hanya sebagai ibu rumah tangga (IRT) berjumlah 30 responden $(44,1 \%)$. Status pekerjaan responden menunjukkan mayoritas responden tidak bekerja (sebagai ibu rumah tangga). Tugas seorang ibu rumah tangga sangat banyak diantaranya yaitu memasak, mencuci, mengurus anak 
dan suami. Hal ini mengakibatkan kelelahan atau letih pada ibu yang memicu penurunan produksi ASI (Hardiani, 2017).

Tabel 4.Distribusi responden berdasarkan status partus ibu post partum di RSIA kasih ibu manado

\begin{tabular}{cccc}
\hline Status Partus & \multicolumn{2}{c}{ n } & \% \\
\hline Primipara & P1 & 27 & 39,7 \\
Multipara & P2 & 29 & 60,3 \\
& P3 & 11 & \\
& P5 & 1 & \\
\hline Total & & $\mathbf{6 8}$ & $\mathbf{1 0 0 , 0}$ \\
\hline
\end{tabular}

Sumber : Data Primer, 2018

Hasil penelitian menunjukan bahwa dari 68 responden didapati responden terbanyak dengan status partus multipara berjumlah 41 responden $(60,3 \%)$, dan primipara berjumlah 27 responden (39,7\%). Dari 41 responden multipara yang mengalami kecemasan 28 responden $(68,3 \%)$ dan tidak cemas 13 responden $(31,7 \%)$, tetapi untuk primipara berjumlah 27 responden dan yang mengalami kecemasan hampir sebagian besar primipara yaitu berjumlah 25 responden $(92,6 \%)$ dan tidak cemas 2 responden $(7,4 \%)$.

Tingkat kecemasan dalam proses menyusui ibu primipara dan multipara berbeda, ibu primipara mengalami kecemasan lebih tinggi dari pada ibu multipara. Kebanyakan ibu primipara khawatir memikirkan bagaimana kehidupannya kelak saat merawat dan mengasuh bayinya. Ibu primipara masih perlu beradaptasi dengan keadaannya setelah proses persalinan sedangkan untuk ibu multipara sudah terbiasa dengan hadirnya anggota keluarga baru (Bentelu, 2015)
Tabel 5.Distribusi responden berdasrkan kecemasan ibu post partum di RSIA kasih ibu manado

\begin{tabular}{ccc}
\hline Kecemasan & n & \% \\
\hline Tidak cemas & 15 & 22,1 \\
Cemas ringan & 24 & 35,3 \\
Cemas sedang & 9 & 13,2 \\
Cemas berat & 15 & 22,1 \\
Panik & 5 & 7,4 \\
\hline Total & $\mathbf{6 8}$ & $\mathbf{1 0 0 , 0}$ \\
\hline Sumber : Data Primer, 2018 &
\end{tabular}

Hasil penelitian menunjukan bahwa dari 68 responden didapati sebagian responden mengalami kecemasan ringan berjumlah 24 responden $(35,3 \%)$. Rasa cemas dapat menimbulkan berbagai masalah, termasuk salah satunya depresi post partum pada ibu, dimana keadaan psikosis ibu terganggu. Adapun depresi post partum merupakan suatu keadaan psikosis mendadak. Psikosis adalah suatu kondisi gangguan jiwa yang ditandai dengan adanya ketidakmampuan membedakan realita dan khayalan (Videbeck \& Sheila, 2008).

Tabel 6.Distribusi responden berdasarkan kelancaran ASI ibu post partum di RSIA kasih ibu manado

\begin{tabular}{ccc}
\hline Kelancaran ASI & n & \% \\
\hline Lancar & 28 & 41,2 \\
Kurang Lancar & 40 & 58,8 \\
\hline Total & $\mathbf{6 8}$ & $\mathbf{1 0 0 , 0}$ \\
\hline Sur
\end{tabular}

Sumber : Data Primer, 2018

Hasil penelitian menunjukan bahwa dari 68 responden didapati responden dengan ASI lancar berjumlah 28 responden $(41,2 \%)$, dan ASI kurang lancar berjumlah 40 responden $(58,8 \%)$. Ibu yang ASInya tidak lancar disebabkan oleh beberapa faktor diantaranya ibu yang mengalami kelelahan setelah persalinan baik Sectio Caesarea maupun spontan pervaginam, kebanyakan ibu merasa takut untuk mobilisasi, sehingga ibu merasa malas menyusui bayinya dan pada akhirnya ibu memilih untuk memberikan susu formula pada bayinya (Amalia, 2016). 
Tabel 7.Hasil Analisi Hubungan Kecemasan dengan Kelancaran Pengeluaran ASI pada Ibu Post Partum di Rumah Sakit Ibu dan Anak Kasih Ibu Manado

\begin{tabular}{|c|c|c|c|c|c|c|c|}
\hline \multirow{3}{*}{ Kecemasan } & \multicolumn{6}{|c|}{ Kelancaran ASI } & \multirow{3}{*}{$\rho$ - Value } \\
\hline & \multicolumn{2}{|c|}{ Lancar } & \multicolumn{2}{|c|}{$\begin{array}{l}\text { Kurang } \\
\text { Lancar }\end{array}$} & \multicolumn{2}{|c|}{ Total } & \\
\hline & $\mathrm{n}$ & $\%$ & $\mathrm{n}$ & $\%$ & $\mathrm{n}$ & $\%$ & \\
\hline Tidak cemas & 10 & 66,7 & 5 & 33,3 & 15 & 100 & \\
\hline Cemas ringan & 11 & 45,8 & 13 & 54,2 & 24 & 100 & \\
\hline Cemas sedang & 6 & 66,7 & 3 & 33,3 & 9 & 100 & 001 \\
\hline Cemas berat & 1 & 6,7 & 14 & 93,3 & 15 & 100 & \\
\hline Panik & 0 & 0 & 5 & 100 & 5 & 100 & \\
\hline Total & 28 & 41,1 & 40 & 58,8 & 68 & 100 & \\
\hline
\end{tabular}

Sumber : Data Primer, 2018

Analisis hasil uji hipotesa dari kecemasan dengan kelancaran pengeluaran ASI menggunakan uji statistik Chi - Square $\left(\chi^{2}\right)$ dan dilanjutkan dengan uji Fisher Exact pada tingkat kemaknaan 95\% $(\alpha=0,05)$, dari hasil penelitian yang telah dilakukan menunjukan adanya hubungan yang signifikan antara kecemasan dengan kelancaran pengeluaran ASI di Rumah Sakit Ibu dan Anak Kasih Ibu Manado. Dimana nilai $\rho$ - Value $=0,001$ lebih kecil dari $\alpha=0,05$.

Hal ini sesuai dengan penelitian yang dilakukan sebelumnya oleh Febrina (2011) hubungan tingkat kecemasan pada primipara dengan kelancaran pengeluaran ASI pada 2-4 hari postpartum di wilayah kerja puskesmas kecamatan lubuk kilangan dengan skor sebagian besar $(73,3 \%)$ responden mengalami kecemasan ringan dan sebagian besar $(66,7 \%)$ mengalami pengeluaran ASI tidak lancar.

Berdasarkan hasil penelitian terdapat 5 responden yang tidak mengalami kecemasan tetapi ASInya kurang lancar, hal ini disebabkan karena 5 responden tersebut melakukan persalinan secara sectio caesarea. Persalinan sectio caesarea bisa mempengaruhi kelancaran pengeluaran ASI, karena seringkali ibu yang melahirkan secara sectio caesarea memiliki kesulitan untuk menyusui bayinya setelah bayi lahir. Terutama untuk ibu yang diberikan anastesi secara umum, ibu akan mengalami penurunan kesadaran untuk mengurus bayinya pada jam pertama setelah bayi lahir (Sari, 2015). Selain itu terjadinya luka pada tindakan pembedahan sectio caesarea akan mengakibatkan nyeri yang lebih berat dibadingkan dengan ruptur atau episiotomy pada daerah pirenium saat melahirkan pervagina (Warsini, Aminingsih \& Fahrunnisa, 2015).

Hasil penelitian terdapat beberapa responden yang mengalami kecemasan tetapi ASInya lancar, hal ini disebabkan karena sebagian besar responden tersebut adalah ibu multipara yang sebelumnya sudah punya pengalaman memberikan ASI. Peneliti beranggapan bahwa beberapa responden tersebut merasa cemas akibat proses persalinan dan ASI lancar karena sebelumnya sudah punya pengetahuan dan pengalaman dalam memberikan ASI. Seperti yang dikatakan oleh Fauziah (2009) laktasi kedua dan ketiga yang dialami ibu berarti ibu telah memiliki pengalaman dalam menyusui anaknya.

Wawancara yang peneliti lakukan, kebanyakan ibu yang mengalami kecemasan khawatir memikirkan bagaimana cara mengasuh bayinya kelak, khususnya untuk ibu primipara mereka khawatir karena belum punya pengalaman mengurus bayi dan perlu beradaptasi dengan keadaan karena telah hadir anggota keluarga yang baru. Sebagian ibu lainnya mengatakan cemas dan takut karena tidak bekerja, karena mereka beranggapan mempunyai bayi itu butuh biaya yang cukup banyak untuk membeli perlengkapan bayi dan sebagainya.

Hawari (2011) menyatakan bahwa kecemasan adalah gangguan alam perasaan yang ditandai dengan perasaan ketakutan atau kekhawatiran yang mendalam. Gejala yang dikeluhkan didominasi oleh faktor psikis tetapi dapat pula oleh faktor fisik. Seseorang akan mengalami gangguan cemas manakala yang bersangkutan tidak mampu mengatasi stressor psikososial.

Ibu pasca persalinan harus mempersiapkan diri untuk menyusui bayinya, tetapi sebagian ibu mengalami 
kecemasan sehingga mempengaruhi kelancaran ASI. Ibu menyusui harus berpikir positif dan rileks agar tidak mengalami kecemasan dan kondisi psikologis ibu menjadi baik, kondisi psikologis yang baik dapat memicu kerja hormon yang memproduksi ASI. Sesuai dengan hasil penelitian yang dilakukan oleh Kamariyah (2014) bahwa terdapat hubungan antara kondisi psikologis ibu dengan kelancaran produksi ASI, keadaan psikologis ibu yang baik akan memotifasi untuk menyusui bayinya sehingga hormon yang berperan pada produksi ASI akan meningkat karena produksi ASI dimulai dari proses menyusui dan akan merangsang produksi ASI.

Berdasarkan hasil penelitian dan teori pendukung, peneliti beranggapan bahwa kecemasan yang terjadi pada ibu post partum karena terlalu memikirkan halhal negatif. Ibu post partum harus berfikir positif, berusaha untuk mencintai bayinya, dan rileks ketika menyusui. Ketika ibu berfikir positif dan tetap tenang akan memicu produksi ASI sehingga ASI bisa keluar dengan lancar, sebaliknya ibu yang kondisi psikologisnya terganggu seperti merasa cemas akan mempengaruhi produksi ASI sehingga produksi ASI bisa menurun dan menyebabkan ASI kurang lancar.

\section{SIMPULAN}

Hasil kesimpulan dari pembahasan tentang hubungan kecemasan dengan kelancaran pengeluaran ASI pada ibu post partum selama dirawat di Rumah Sakit Ibu dan Anak Kasih Ibu Manado tahun 2018, bahwa sebagian besar responden mengalami kecemasan ringan, sebagian besar responden ASI nya kurang lancar. Ada hubungan antara kecemasan dengan kelancaran pengeluaran ASI pada ibu post partum selama dirawat di Rumah Sakit Ibu dan Anak Kasih Ibu Manado.
DAFTAR PUSTAKA

Amalia, R. (2016). Hubungan Stres Dengan Kelancaran ASI Pada Ibu Menyusui Pasca Persalinan di RSI A.Yani Surabaya. Diakses pada 27 November 2018. Diakses pada 28 November 2018

Aprilia, Y. (2011). Hipnostetri. Rileks Nyaman dan Aman saat Hamil dan Melahirkan. Jakarta: Gagas Media. Diakses pada tanggal 14 September 2018

Badriah, D. L. (2011). Gizi dalam Kesehatan Reproduksi. Bandung: PT Refika Aditama. Diakses pada tanggal 14 September 2018

Bentelu, F.E.M. (2015). Perbedaan Tingkat Kecemasan Dalam Proses Menyusui Antara Ibu Primipara dan Multipara di RS Pancaran Kasih GMIM Manado. Diakses pada 26 November 2018

Dinas Kesehatan Daerah Provinsi Sulawesi Utara. (2016). Profil Kesehatan Provinsi Sulawesi Utara.

Fauziah. (2009). Faktor-faktor yang Berhubungan Dengan Waktu Menyusui Pertama Kali Pada Bayi Baru Lahir di Rumah Sakit Umum Daerah Kota Jakarta. Diakses pada 15 Desember 2018.

Febrina, I. (2011). Hubungan Tingkat Kecemasan Pada Primipara Dengan Kelancaran Pengeluaran ASI Pada 2-4 Hari Postpartum Di Wilayah Kerja Puskesmas Kecamatan Lubuk Kilangan. Diakses pada 26 November 2018

Hardiani, R.S. (2017). Status Paritas dan Pekerjaan Ibu Terhadap Pengeluaran ASI Pada Ibu Menyusui 0-6 Bulan. Diakses pada 26 Oktober 2018. 
e-journal Keperawatan (e-Kp) Volume 7 Nomor 1, Februari 2019

Hartini, S. (2014). Hubungan Tingkat Pendidikan Ibu Dengan Keberhasila ASI Eksklusif Pada Bayi Umur 6-12 Bulan di Puskesmas Kasihan II Yogyakarata. Diakses pada 27 November 2018

Hawari, R. P. (2011). Management Stress, Cemas dan Depresi. Jakarta : FK UI.

Kamariyah, N. (2014). Kondisi Psikologis Mempengaruhi Produksi ASI Ibu Menyusui Di BPS Aski Pakis Sido Kumpul Surabaya Diakses pada 27 November 2018

Kementrian Kesehatan Republik Indonesia. (2016). Profil Kesehatan Indonesia.

Pusat Data dan Informasi Kementrian Kesehatan RI. (2014). Situasi dan Analisis ASI EKSKLUSIF.

Qiftiyah, M. (2017). Studi Tingkat Kecemasan Ibu Post Partum Terhadap Kelancara ASI Pada Ibu Nifas Hari Ke-5 (Di BPM Asri Dan Polindres Permata Bunda Tuban). Diakses pada 10 September 2018.

Riksani, R. (2012). Keajaiban ASI (Air Susu Ibu). Jakarta Timur: Dunia Sehat

Sari, L.W. (2015). Hubungan Jenis Persalinan dengan Onset Laktasi Pada Ibu Post Partum di RS PKU Muhammadyah Yogyakarta. Diakses pada 4 Desember 2018

Sulastri, W. (2016). Hubungan Tingkat Kecemasan Dengan Pemberian ASI Pada Masa Nifas Di Puskesmas Umbuhlharjo 1 Yogyakarta Tahun 2016. Diakses pada 13 September 2018 .

Videbeck., \& Sheila, L. (2008). Buku Ajar Keperawatan Jiwa. Jakarta : EGC
Warsini., Aminingsih, S., \& Fahrunnisa, R.A. (2015). Hubungan Antara Jenis Persalinan dengan Keberhasilan ASI Eksklusif di Kecamatan Baki Kabupaten Sukoharjo. Diakses pada 4 Desember 2018

Wiji, R.N. (2013). ASI dan Panduan Ibu Menyusui. Yogyakarta: Nuhu Medika

Wulandari, I.H. (2014). Tingkat Kecemasan Ibu Postpartum Yang Asinya Tidak Lancar di Ruang Bersalin RSUD DR. Abdoer Rahem Situbondo. Diakses pada 10 September 2018. 